\title{
Comparison of Thermal Performance of Newly Produced Lightweight Wall and Roof Elements for Energy-efficient Buildings
}

\author{
Hasan Oktay ${ }^{1}$ Decep Yumrutas $^{2}$ (D) $^{\text {Zeki Argunhan }}{ }^{3}$ \\ ${ }^{1}$ Batman University, Department of Mechanical Engineering, Batman, Turkey \\ ${ }^{2}$ Gaziantep University, Department of Mechanical Engineering, Gaziantep, Turkey \\ ${ }^{3}$ Bitlis Eren University, Department of Mechanical Engineering, Bitlis, Turkey
}

\section{A BS T RACT}

$\mathrm{n}$ this study, both experimental and theoretical investigations are performed to obtain new concrete types with high thermal insulating characteristics for energy-efficient buildings. In this regard, 102 new concrete wall samples were produced using different aggregates at different volume fractions, and their thermophysical properties were tested according to EN and ASTM standards. The experimental research focused on developing new wall or roof types with higher thermal insulation properties in order to reduce the energy consumption of buildings due to heating or cooling. In order to specify the thermal performance of developed lightweight concretes, an analytical solution method is developed by the Complex Finite Fourier Transform (CFFT) method to estimate heat gain utilizing measured thermophysical properties data of those samples. The results indicated that the reduction in heat gain value was obtained as $83.21 \%$ for the PC100 wall corresponding to conventional concrete. Consequently, the thermal insulation effect of those samples shows excellent potential for development.

\section{Keywords:}

Energy-efficient buildings, Concrete, Heat gain, Thermophysical properties, CFFT
Article History:

Received: 2019/11/19

Accepted: 2020/03/17

Online: $2020 / 03 / 26$

\author{
Correspondence to: Hasan Oktay \\ Batman University, Department of \\ Mechanical Engineering, Batman, Turkey \\ Tel: +904882173991 \\ Fax: +904882173502 \\ E-Mail:hasan.oktay@batman.edu.tr
}

\section{INTRODUCTION}

$\mathrm{T}$ he building sector is responsible for the enormous amount of total energy consumption in the World. Most of this energy is used for the provision of heating and cooling applications. The main objective of a cooling or heating system is to maintain the thermal comfort conditions to the occupants of the building that are required for indoor products and processes. The heat ratio that must be removed from a room to maintain a stable temperature at the comfort level is defined as a cooling load [1]. The heat gain through the building envelope, which includes roofs and walls in most buildings, constitutes a significant partition of the overall cooling load of space due to its large area [2]. If the structures having appropriate thermal properties are selected, also accurate cooling load calculation is performed, and then suitable HVAC system components can be selected. Therefore, estimation of the cooling load through the building envelope is an essential task in the selection of proper components of an HVAC system that influences the building's performance. However, an accurate calculation of the cooling load is quite complicated and time-consuming due to the thermal storage effects of a building thermal mass and continuously changing outdoor climatic conditions [3].

In literature, several methods have been developed to calculate the cooling load due to heat gain through the envelope such as transfer function method (TFM), heat balance method (HB), total equivalent temperature difference method (TETD), and cooling load temperature difference (CLTD) method. TFM, which is widely used in HVAC industry [4], uses a set of design types with recalculated conduction transfer functions (CTF) coefficients tabulated for certain types of walls, ceilings, and floors handbook of ASHRAE [5]. The calculation of heat gain by the CLTD method is provided by multiplying the UA value of a building envelope with the CLTD values obtained by using the HB or TFM technique. It is limited by the data for specific constructions used in North America with particular external conditions [2]. On the other hand, Complex Finite Fourier Transform (CFFT) is a new model and analytically provides a transformation of the problem into a form that leads to 
a transient solution. Zainal and Yumrutas [6] used the CFFT technique to find the CLTD values numerically for multilayered roofs and walls. A one-dimensional solution to the transient problem is a new approach to estimate CLTD values. By the way, CFFT is applicable for any possible building structure and ever-changing outdoor climatic conditions, and also it does not require the tables.

Concrete is the most widely used construction material in the world due to its internal functionality and the presence of raw materials used in its production [7-8]. It is essential to improve the thermophysical properties of concrete to reduce the heating and cooling energy consumption of buildings. The important thermophysical properties for heat-transfer processes of a building are density, specific heat, thermal conductivity, and thermal diffusivity. Notably, a low conductivity is required due to the ability to provide thermal insulation, and high specific heat is required due to the ability to retain heat [8]. Besides, the thermophysical properties of concrete depend on moisture content, type, and proportion of aggregate and cement materials $[9,10]$. Since aggregates generally comprise about $70-80 \%$ of the concrete volume, these materials can be expected to have a more significant effect than other parameters [11]. Many studies have discussed in literature about the influences of type and proportion of aggregate on thermophysical properties of concrete. An experimental study [12] was carried out with several types of aggregates to investigate the influence of the aggregate on the thermal properties of concrete. Results showed that concrete containing pieces of calcined clay bricks showed a lower thermal conductivity, but a higher specific heat than concrete containing stone chips. Besides, the thermal conductivity of produced concretes was directly proportional to their thermal diffusivities. Różycka and Pichór [13] studied the effect of perlite waste addition on the properties of autoclaved aerated concrete. The results showed that due to its high insulation properties, expanded perlite waste could potentially be used as a replacement in the production of autoclaved aerated concrete. Benazzouk et al. [14] were conducted a study about the influence of waste rubber particles on the thermal properties of concrete. The results indicated that the addition of rubber particles to concrete reduces thermal conductivity and density. Kilincarslan et al. [15] reported that the addition of pumice to foam concrete reduces thermal conductivity and bulk density. Besides, many studies have been revealed that thermal insulation characteristics of masonry materials are improved by introducing various amounts of lightweight and synthetic aggregates and also some additives [16-18]. Although many researchers have studied the thermal properties of concretes containing different types of lightweight aggregates, there has not been much in the literature to identify the effects of insulation properties for a given climate.
In this study, experimental and theoretical studies are performed. The experimental research focused on developing new wall or roof types with higher thermal insulation properties in order to minimize the energy consumption of buildings. The calculation method for the cooling load used in the study is based on the solution of the periodic heat transfer problem in order to obtain the temperature distribution of the multilayer wall or flat roof structures.

\section{MATERIAL AND METHODS}

Several materials were used to obtain different lightweight building wall or roof elements. The materials were locally available fine aggregate, coarse aggregate, ordinary Portland cement, mineral admixtures such as silica fume, superplasticizers, and lightweight aggregates such as rubber aggregate (RA), pumice aggregate (PA) and expanded perlite aggregate (EPA). The concrete mixtures were prepared with a constant water-cement ratio of 0.48 and total cement content of $350 \mathrm{~kg} / \mathrm{m}^{3}$. The value of 0.48 was selected for providing desired consistency in the mixtures [19]. Then, aggregates were replaced by RA, EPA, and PA at different volume fractions (10\%, 20\%, 30\%, 40\%, $50 \%$, and $100 \%$ ) of the total aggregate volume. Besides, a control mix with no replacement of the light-weight aggregate was produced to make a comparative analysis. The chemical composition of the materials used in the study and mix proportions are detailed in Ref. [20]. During the mixing process, the target air content was established at $2 \%$ for the control concrete and $6 \%$ for the air-entrained concrete. The same series of calculations accomplished by the volume to weight conversions for aggregates. The actual material quantities were then calculated by using the following equations:

$$
\begin{aligned}
& \mathrm{V}_{\mathrm{a}}=1-\left(\frac{\mathrm{C}}{\delta_{\mathrm{c}}}+\frac{\mathrm{W}}{\delta_{\mathrm{s}}}+\mathrm{h}+\mathrm{k}\right) \\
& \mathrm{W}=\left(\frac{\mathrm{E}}{\mathrm{C}}\right) \times \mathrm{C} \\
& G_{i}=V_{a} x P_{i} x \delta_{i}
\end{aligned}
$$

where $\mathrm{V}_{\mathrm{a}}$ is total aggregate volume in concrete $\left(\mathrm{m}^{3}\right), \mathrm{C}$ is weight of cement $(\mathrm{kg}), \mathrm{W}$ is weight of water $(\mathrm{kg})$, h is targeted air volume in concrete $\left(\mathrm{m}^{3}\right), \mathrm{k}$ is admixtures volume in concrete $\left(\mathrm{m}^{3}\right), \mathrm{E} / \mathrm{C}$ is effective water/cement ratio, $\delta_{c}$ and $\delta_{\mathrm{i}}$ are specific gravity of cement and aggregates $\left(\mathrm{kg} / \mathrm{m}^{3}\right)$, respectively. Then, the concrete mixes were prepared in a laboratory in the following order:

Firstly, PA and EPA were pre-wetted for $30 \mathrm{~min}$. - Secondly, one-third of water and light-weight aggregate were mixed. 
- $\quad$ Thirdly, cement, mineral admixtures were mixed with remaining water.

- $\quad$ Finally, stirring was continued until a uniform concrete was produced.

The mixture was first mixed for 5 min in a mixer and then placed in the mold, and it was adequately compacted for $2 \mathrm{~min}$ on a vibration table (Fig. 1). The mixtures were produced as expanded perlite concrete (EPC), rubberized concrete (RC), pumice concrete (PC), normal concrete (NC), air-entrained concrete (AEC) and the numbers as 10, 20, 30, 40, 50 and 100 show the percentage of replacement. In total, 102 concrete samples were produced, and their mechanical tests such as the compressive strength (ASTM C39, as shown in Fig. 2), bulk density (ASTM C138) and porosity tests (ASTM C1202-12) were performed in accordance with ASTM standards on air-dry samples aged 28 days (ASTM C330-99). The minimum strength requirements for building blocks are most commonly set at $2.5 \mathrm{MPa}$ [21]. Therefore, the produced samples whose compressive strengths are under the limit were not included in the study (EPC100 and RC100 were not cased).

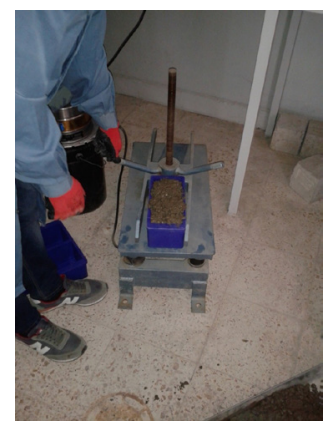

Figure 1. Vibrating Table

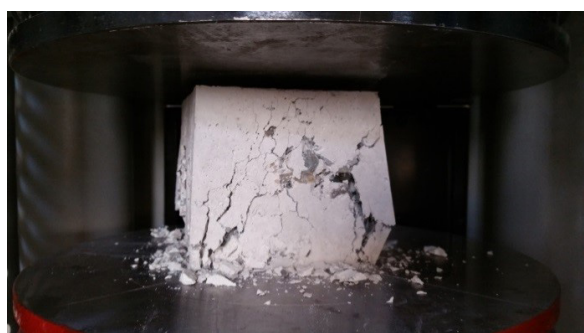

Figure 2. The compressive strength test (ASTM C39)

In order to establish thermophysical properties of the concretes, thermal conductivity, thermal diffusivity, and specific heat tests were performed by transient plane source technique (TPS) according to EN 12667. The advantage of the TPS method compared to stationary or steady-state methods is to determine a full set of thermophysical properties within a single measurement. The values of the thermal property device range for measuring parameters are given in Table 1. ISOMET 2104 device was used to measure the thermal property of concrete samples based on the transient plane source method, as indicated in Fig. 3.
Table 1. Values of device range for measuring parameters

\begin{tabular}{|c|c|c|}
\hline $\begin{array}{c}\text { Measurement } \\
\text { property }\end{array}$ & Measurement range & Accuracy \\
\hline $\begin{array}{c}\text { Thermal } \\
\text { conductivity }\end{array}$ & $0.015-6 \mathrm{~W} / \mathrm{mK}$ & $5 \%$ of reading $\pm 0.001 \mathrm{~W} / \mathrm{mK}$ \\
\hline $\begin{array}{c}\text { Specific heat } \\
\text { capacity }\end{array}$ & $4 \times 10^{4}-4 \times 10^{6} \mathrm{~J} / \mathrm{m}^{3} \mathrm{~K}$ & $15 \%$ of reading $\pm 1.103 \mathrm{~J} / \mathrm{m}^{3} \mathrm{~K}$ \\
\hline $\begin{array}{l}\text { Thermal } \\
\text { diffusivity }\end{array}$ & $4 \times 10^{-5}-4 \times 10^{-8} \mathrm{~m}^{2} / \mathrm{s}$ & $10 \%$ of reading $\pm 0.1 \times 10^{-8} \mathrm{~m}^{2} / \mathrm{s}$ \\
\hline $\begin{array}{l}\text { Operating } \\
\text { temperature }\end{array}$ & From $-20-+70^{\circ} \mathrm{C}$ & $1^{\circ} \mathrm{C}$ \\
\hline
\end{tabular}

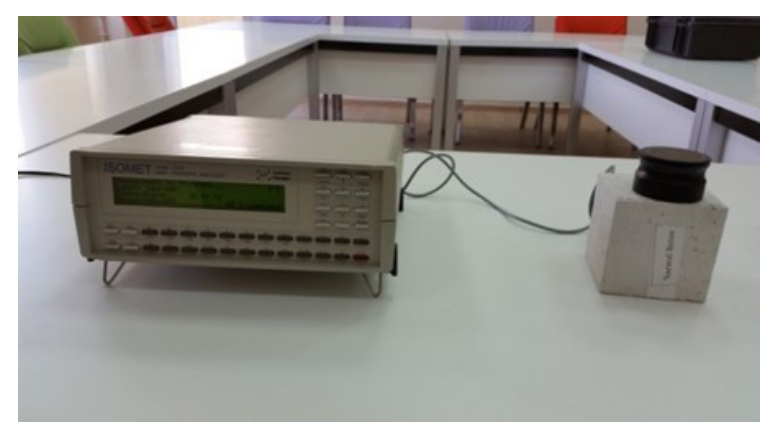

Figure 3. The measurement devices of the thermal property

\section{Formulation of Heat Transfer Problem}

In order to decide whether any one of the building wall or roof elements is the best or not due to heat transfer, it is necessary to compare heat gain or loss for these elements. In this study, at first, the heat gain values through the produced wall or roof structures are estimated, and then the estimated heat gain values for each element are compared with other building elements. Since the magnitude of energy consumption in heating and cooling of any space is extremely important for humanity or environment protection or pollution, any element or elements having the lowest heat gain values are recommended to applicants.

Heat gain, $\mathrm{q}_{\mathrm{c}}\left(\mathrm{W} / \mathrm{m}^{2}\right)$ through indoor space of a building from exterior walls or roofs can be calculated using the inner wall surface, room temperature, $\mathrm{T}_{\mathrm{r}}$ and combined convection heat transfer coefficient at the inner surface, $h_{i}$ :

$$
q_{c}=h_{i}\left[T_{1}(0, t)-T_{r}\right]
$$

In the present study, inner surface temperature, $\mathrm{T}_{1}(0, \mathrm{t})$ is a function of coordinate and time obtained from a general solution of transient heat transfer problem. The building wall or roof consisting of $\mathrm{N}$ layers is shown in Fig. 4.

Formulation of periodic heat transfer from a building structure to a room is presented as the following partial equations under given boundary conditions: 


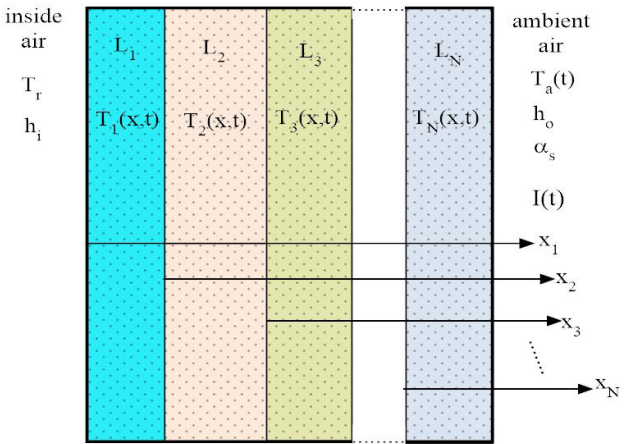

Figure 4. Schematic view of a multilayer wall or flat roof

$\frac{\partial^{2} T_{n}}{\partial x_{n}^{2}}=\frac{1}{\alpha_{n}} \frac{\partial T_{n}}{\partial t} \quad 1 \leq n \leq N$

$h_{i}\left(T_{r}-T_{1}\right)=-k_{1} \frac{\partial T_{1}}{\partial x_{1}}\left(x_{1}=0\right) \quad$ at $X_{1}=0$

$k_{n-1} \frac{\partial T_{n-1}}{\partial x_{n-1}}\left(x_{n-1}=L_{n-1}\right)=k_{n} \frac{\partial T_{n}}{\partial x_{n}}\left(x_{n}=0\right) \quad 2 \leq n \leq N$

$\mathrm{T}\left(x_{n-1}=L_{n-1}\right)=\mathrm{T}\left(x_{n}=0\right) \quad 2 \leq n \leq N$

$-k_{N} \frac{\partial T_{N}}{\partial x_{N}}\left(x_{N}=L_{N}\right)=h_{o}\left[T_{N}-T_{e}(t)\right] \quad$ at $X_{N}=L_{N}$

$T_{e}(t)=T_{a}(t)+\frac{\alpha_{s} I_{t}(t)}{h_{o}}-\frac{R}{h_{o}} \quad$ at $\quad X_{N}=L_{N}$

where $\Delta \mathrm{R}$ is the difference between the long-wave radiation incident from the sky and the radiation incident emitted by a blackbody at the ambient air temperature. ASHRAE recommends the correction factor, $\varepsilon \Delta R / h_{o}$ to be given a value of $4^{\circ} \mathrm{C}$ and $0^{\circ} \mathrm{C}$ for horizontal surfaces and vertical surfaces, respectively.

The heat transfer problem consists of Eqs. (5)-(10) is transformed into dimensionless formulations, and then CFFT is applied to obtain the general solution of the problem and is expressed as:

$$
T_{n}\left(z_{n}, \tau\right)=\sum_{j=-M}^{M} T_{n j}\left(z_{n}\right) e^{i \omega_{j} \tau} \quad \omega_{j}=2 \pi j
$$

where $T_{1}(0, t)$ is the inner surface temperature of the roof or wall obtained from Eq. (8) at $\mathrm{z}_{\mathrm{n}}=0$ and expressed as:

$$
T_{1}(0, \mathrm{t})=\sum_{j=-M}^{M} T_{1 \mathrm{j}}(0) e^{\mathfrak{u}_{j} \tau} \quad \text { at } Z_{n}=0
$$

where $T_{1 j}(0)$ is a dimensionless parameter. Its expression and calculation procedure are presented in Yumrutaş et al. $[1,3] . T_{n}\left(z_{n}, \tau\right)$, given by Eq. (11), is a periodic solution of the temperature distribution in a wall and is obtained as a function of solar radiation incident on a tilted surface and ambient air temperature, $\mathrm{T}_{\mathrm{a}}(\mathrm{t})$. $\mathrm{I}_{\mathrm{T}}(\mathrm{t})$ is the intensity of solar radiation incident falling on the unit area and can be defined as a sum of the diffuse, beam, and reflected radiation [22].

$I_{T}(t)=I_{b}(t) R_{b}+I_{d}(t)\left(\frac{1+\cos \beta}{2}\right)+I(t) \rho_{g}\left(\frac{1-\cos \beta}{2}\right)$

where $I_{d}(t)$ and $I_{b}(t)$ are diffuse and beam radiation on a horizontal surface. $\rho_{\mathrm{g}}$ is ground reflectance and taken as 0.2 in the present study. Geometric factor, $\mathrm{R}_{\mathrm{b}}$ can be calculated for vertical surfaces $\left(\beta=90^{\circ}\right)$ as;

$R_{b}=\frac{\cos \delta \sin \varphi \cos \gamma \cos \omega+\cos \delta \sin \gamma \sin \omega-\sin \delta \cos \varphi \cos \gamma}{\cos \varphi \cos \delta \cos \omega+\sin \varphi \sin \delta}$

where, $\phi, \omega, \gamma$ and $\delta$ are the latitude, hour, azimuth and declination angles, respectively [22].

\section{COMPUTATIONAL PROCEDURE}

In order to find the best-produced sample in terms of heat transfer, heat gain through the samples is estimated by utilizing the solution of transient heat transfer problem for a wall or roof. In this regard, a computer program in MATLAB was prepared by using climatic data, which are hourly ambient air temperature and solar radiation on a horizontal surface, and thermophysical properties of the produced samples. The climatic data were obtained at the meteorological stations for Gaziantep province (latitude: $37.04{ }^{\circ} \mathrm{N}$, longitude: $37.31^{\circ} \mathrm{E}$ ) on July 21. By utilizing the program, hourly solar radiation incident on a vertical surface with different direction is calculated by using Eq. (13). The room temperature, the inner and outer surface combined heat transfer coefficients are taken as $25^{\circ} \mathrm{C}, 8.3$, and $17 \mathrm{~W} / \mathrm{m}^{2 \circ} \mathrm{C}$, respectively. Solar absorptivity $\alpha \mathrm{s}$, which depends on the external face color of a building envelope, is assumed to be 0.8 (dark-colored surface). The hourly sol-air temperature and the other constant parameters were given as input data. When the program is first executed, the hourly sol-air temperature in Eq. (10) is computed, and then the inner surface temperature and heat gain through the wall or roof are computed by Eqs. (12) and (4), respectively.

\section{RESULTS AND DISCUSSION}

Both experimental and theoretical investigations are performed in this study to find the best wall or roof material 
Table 2. Mechanical and thermal properties of produced concrete samples.

\begin{tabular}{|c|c|c|c|c|c|}
\hline $\begin{array}{l}\text { Types of } \\
\text { concrete }\end{array}$ & $\begin{array}{c}\text { Compressive } \\
\text { strength } \\
\sigma(\mathrm{MPa})\end{array}$ & $\begin{array}{c}\text { Bulk density, } \\
\rho(\mathrm{kg} / \mathrm{m} 3)\end{array}$ & $\begin{array}{l}\text { Thermal } \\
\text { conductivity } \\
\text { k (W/m K) }\end{array}$ & $\begin{array}{l}\text { Specific } \\
\text { heat } \\
\text { c (J/kg K) }\end{array}$ & $\begin{array}{l}\text { Thermal } \\
\text { diffusivity } \\
\alpha \quad(\mathrm{mm} 2 / \mathrm{s})\end{array}$ \\
\hline $\mathrm{NC}$ & 51.85 & 2345.09 & 1.96 & 709.07 & 1.18 \\
\hline $\mathrm{AEC}$ & 48.11 & 2288.86 & 1.91 & 712.14 & 1.17 \\
\hline EPC10 & 31.21 & 2139.09 & 1.51 & 725.48 & 0.97 \\
\hline EPC20 & 19.02 & 1885.52 & 1.22 & 779.63 & 0.83 \\
\hline ЕРC30 & 10.01 & 1559.44 & 0.70 & 865.69 & 0.52 \\
\hline EPC40 & 8.15 & 1376.56 & 0.50 & 922.59 & 0.40 \\
\hline ЕРC50 & 4.88 & 1168.63 & 0.36 & 966.95 & 0.32 \\
\hline PC10 & 33.46 & 2005.34 & 1.54 & 772.42 & 0.99 \\
\hline PC20 & 23.39 & 1851.02 & 1.29 & 818.52 & 0.85 \\
\hline PC30 & 13.07 & 1559.95 & 0.76 & 903.87 & 0.54 \\
\hline PC40 & 9.90 & 1400.72 & 0.54 & 949.51 & 0.41 \\
\hline PC50 & 9.51 & 1329.97 & 0.41 & 991.80 & 0.31 \\
\hline PC100 & 5.24 & 721.49 & 0.16 & 1221.85 & 0.18 \\
\hline $\mathrm{RC} 10$ & 42.04 & 2244.30 & 1.72 & 721.83 & 1.06 \\
\hline $\mathrm{RC} 20$ & 30.41 & 2148.07 & 1.44 & 737.70 & 0.91 \\
\hline $\mathrm{RC} 30$ & 19.04 & 2033.93 & 1.22 & 761.20 & 0.79 \\
\hline RC40 & 9.51 & 1874.62 & 0.89 & 808.93 & 0.58 \\
\hline RC50 & 4.53 & 1644.98 & 0.62 & 868.16 & 0.43 \\
\hline
\end{tabular}

from produced samples. In the experimental study, new lightweight concrete samples having adequate strength and relatively high thermal insulation properties were produced for energy efficiency. The experimental test results for the thermal diffusivity, compressive strength, bulk density, specific heat, and thermal conductivity are tabulated in Table 2. The experimental results given in Table 2 are obtained based on the average of five tested values with \pm a tolerance limit (less than $2 \%$ ) for each property test. In the theoretical study, the surface temperature of the samples and heat gain values through the structures are calculated by an analytical model utilizing a program in MATLAB. The heat gain calculations are performed for different building structures, and the schematic view of the configurations used in this study is represented in Fig. 5.

In order to evaluate possible correlations between measurement values of the thermophysical properties of building structures, multivariate regression is performed on the dataset of 102 concrete samples (Table 2) using the free statistical software found in Microsoft Excel. A vital correlation given by Eq. (15) was obtained by using the measurement results of thermal conductivity and thermal diffusivity, as depicted in Fig. 6. It is observed that there is a nearly linear relation between the values of thermal diffusivity and conductivity of produced concrete samples and can be expressed by the equation with $\mathrm{R}^{2}=0.99$ :

$$
k=2 \times 10^{6} \alpha-0.1845
$$
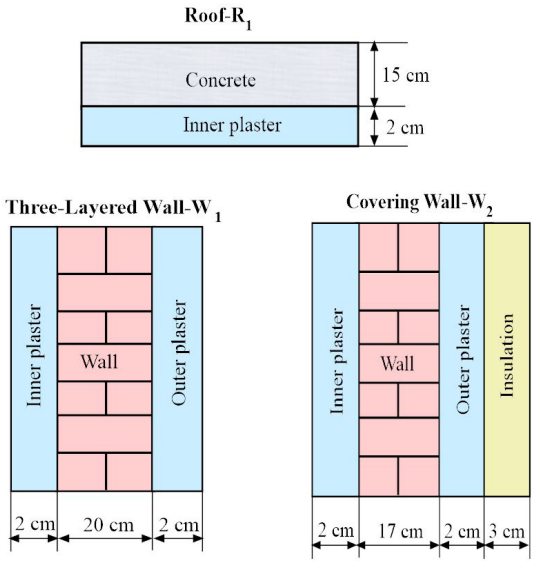

Figure 5. Schematic view of a multilayer wall or flat roof configurations used in this study

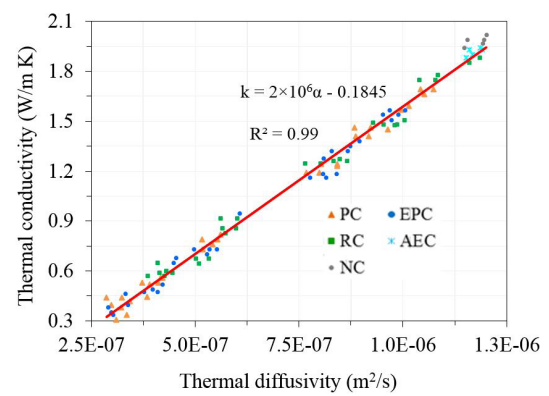

Figure 6. Relationship between the thermal diffusivity and the thermal conductivity obtained experimental study

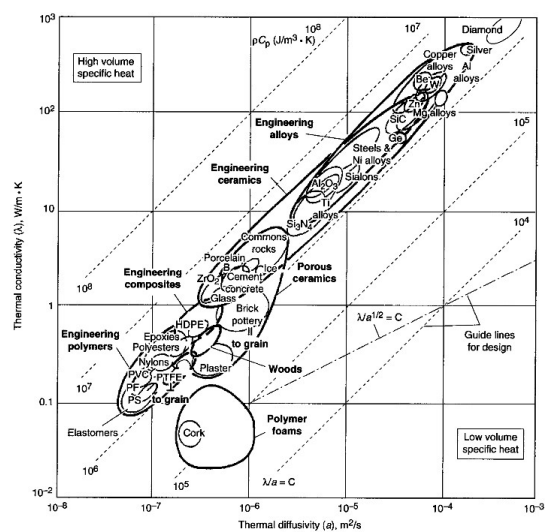

Figure 7. A comprehensive list of building materials: thermal conductivity is plotted against thermal diffusivity for room temperature $[23]$

Besides, the results obtained in the present study were compared with similar studies in the literature (Fig. 7). Thermal conductivity is plotted against the thermal diffusivity for a comprehensive list of building structures [23]. It can be concluded that the relations obtained from this study have a similar tendency to those relations reported in the literature, and covered all other building structures.

In order to estimate temperature distributions on a wall or roof surface, sol-air temperature values should be 
calculated by using hourly ambient air temperature and solar radiation incident on a horizontal surface. Fig. 8 presents the daily variation of sol-air temperatures due to horizontal and vertical surfaces for the city of Gaziantep. The solair temperature values of walls and roofs due to the North, East, West, and South directions are calculated from the Eq. (10) by using the measurement values. The calculated sol-air temperature values for all surfaces behave as quasisymmetric; especially, it can be noticeable in the East and West directions. Besides, it is depicted that values of diffuse radiation for the West are higher than the values for the East. Heat gain fractions in the present study are defined as the ratio of heat gain value of each wall construction to the heat gain value of the reference wall sample.

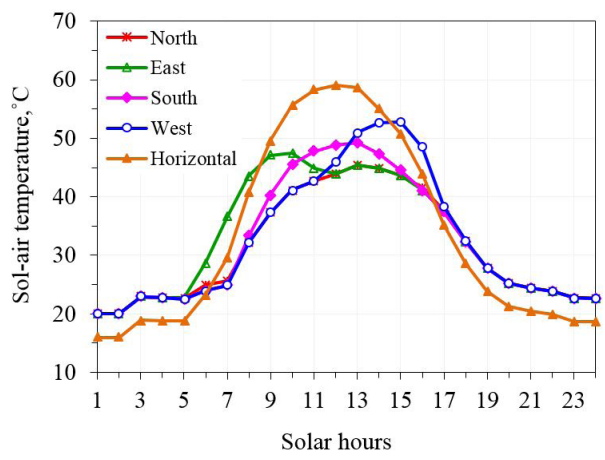

Figure 8. Daily variation of sol-air temperatures due to horizontal and four main vertical surfaces

Fig. 9 shows the variation of heat gain fraction for each wall construction (W1) with respect to aggregate content. It is seen from the results that $83.21 \%$ reduction in heat gain value is obtained using the PC100 wall, corresponding to reference concrete $(\mathrm{NC})$. The lowest value of heat gain results for the lowest thermal conductivity of the PC100 wall. It is understood from the Fig. 9 that the heat gain values for the walls are inversely proportional to the light-weight aggregate ratios. The reduction in heat gain of composites is due to the insulating effect of light-weight aggregate particles having a lower thermal conductivity compared to normal aggregates.

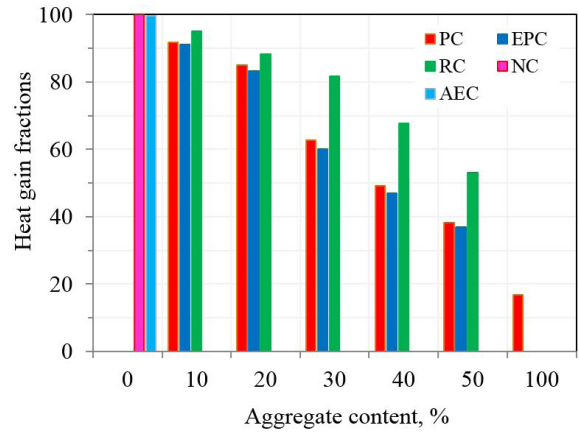

Figure 9. The percentages of max. heat gain fractions for each southwall construction (W1) with different aggregate content

The results of daily heat gain values through the walls

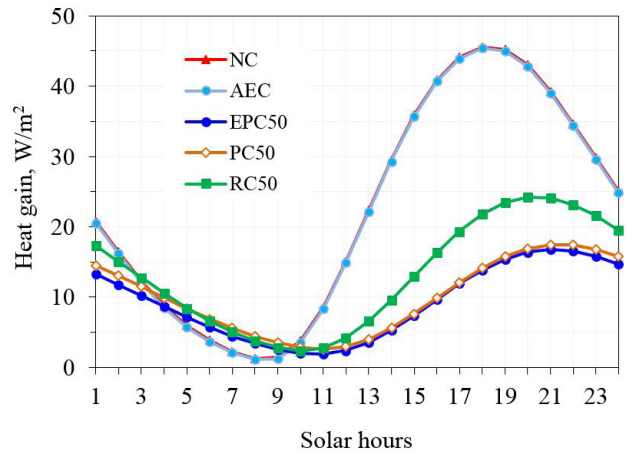

Figure 10. Variation of heat gains for south-facing wall constructions (W1) at the same light-weight aggregate ratios

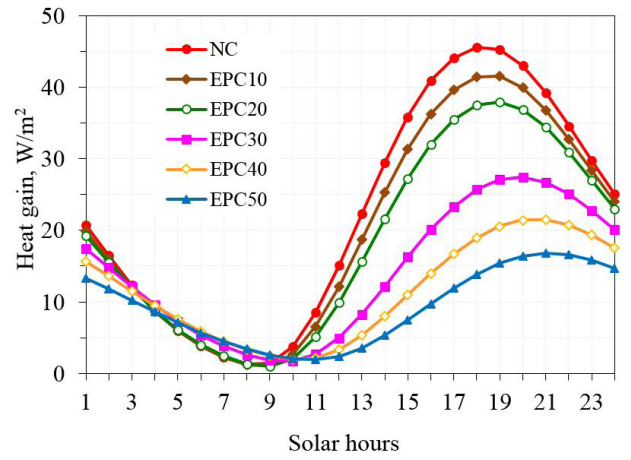

Figure 11. Daily variation of heat gain values of dark-colored NC and EPC walls (W1) with different EPA ratios due to the south direction

(W1) due to south direction are shown in Fig. 10. As shown in this figure, the highest value of heat gain occurs for the $\mathrm{NC}$ wall having the highest value of thermal diffusivity and conductivity. The results show that thermal diffusivity and conductivity of the materials have a profound influence on the thermal performance of the structures. Besides, the AEC wall also has the highest amplitude of heat gain value for the design day, and they are reasonably close to those of the NC wall. In these walls, the lowest values of heat gain value are provided for PC50 and EPC50 walls, of which the values are close to each other. It can be seen that the thermal diffusivity of a sample has a profound effect on heat gain since the thermal diffusivity values of NC, AEC, PC50, and EPC50 are $1.18,1.17,0.32$, and $0.31 \mathrm{~mm}^{2} / \mathrm{s}$, respectively. It is evident from Fig. 10 that the utilization of PC50 or EPC50 as a wall or roof material in a building provides a lower heat gain value and maintains a stable temperature at comfort level compared to $\mathrm{NC}$ and $\mathrm{AEC}$.

Daily variations of heat gain values for the $\mathrm{NC}$ and $\mathrm{EPC}$ walls with different EPA ratios are illustrated in Fig. 11. The $\mathrm{NC}$ wall has the highest amplitude of the heat gain value, and it is followed by EPC10, EPC20, EPC30, EPC40, and EPC50, respectively. The highest values of heat gain are estimated for EPC50 and NC walls with values of $16.796 \mathrm{~W} / \mathrm{m}^{2}$ and $45.598 \mathrm{~W} / \mathrm{m}^{2}$, respectively.

The daily amplitude of inner and exterior surface tem- 
perature differences $\left(\Delta T=T_{e x}-T_{i n}\right)$ for roofs (R1) are shown in Fig. 12. The highest differences in temperature occur in EPC50 roof construction, and the lowest differences in temperature occur in $\mathrm{NC}$ roof construction, having the highest value of thermal diffusivity and conductivity. Furthermore, it can be seen from the figure that heat transfer takes place from the room side to outside air before the hour of 6 and after the hour of 19 . When solar radiation does not exist or is very low, the temperature difference for all constructions is dropped below $0^{\circ} \mathrm{C}$. The reason is that when solar radiation intensity is low, terrestrial objects surfaces usually have a lower temperature than the ambient air; hence, horizontal surfaces receive long-wave radiation from the sky only.

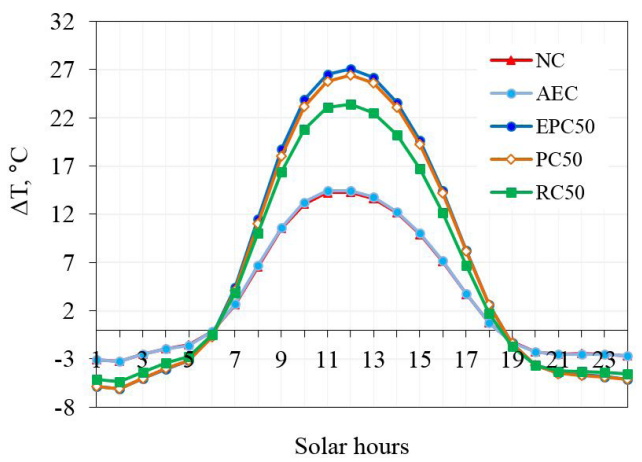

Figure 12. Variation of inner and outer surface temperature differences for roof constructions (R1) at the same light-weight aggregate ratios

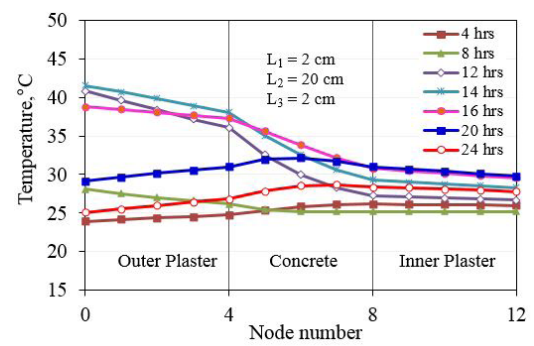

(a)

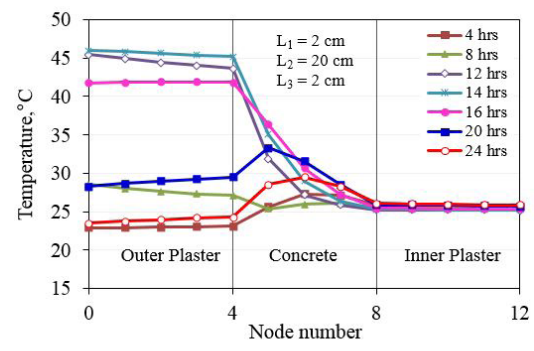

(b)

Figure 13. Temperature distributions across the dark-colored walls due to south direction: (a) NC and (b) PC100 walls

Temperature distributions across the NC, EPC50, and PC100 walls (W1) due to the south direction at various time intervals are shown in Fig. 13 for July 21. After heat fluxes across the EPC50 wall, the temperature on the interior plaster is maintained at a constant level of $25-27^{\circ} \mathrm{C}$. In the case
Table 3. Thermophysical properties of selected wall and roof materials[1]

$\begin{array}{ccccc}\text { Building } & \begin{array}{c}\text { Thermal } \\ \text { conductivity } \\ \text { materials }\end{array} & \begin{array}{c}\text { Density } \\ \mathrm{k}(\mathrm{W} / \mathrm{m} \mathrm{K})\end{array} & \begin{array}{c}\text { Specific } \\ \text { heat } \\ \mathrm{c}\left(\mathrm{kg} / \mathrm{m}^{3}\right)\end{array} & \begin{array}{c}\text { Thermal } \\ \text { diffusivity }\end{array} \\ \begin{array}{c}\text { Plaster } \\ \text { EPS }\end{array} & 0.700 & 2778 & 840 & 0.30 \\ \text { Briquette } & 0.038 & 18 & 1500 & 1.40 \\ \text { Brick } & 0.920 & 1600 & 840 & 0.68 \\ \text { Blockbims } & 0.230 & 1580 & 840 & 0.52 \\ \text { AAC } & 0.150 & 470 & 835 & 0.36 \\ & & 400 & 1047 & 0.36\end{array}$

of the $\mathrm{NC}$ wall, variation of the temperature is unsteady at the interior plaster, and the temperature is maintained at 26$30^{\circ} \mathrm{C}$, which is higher than the comfort temperature. When the wall constructed with $\mathrm{PC100,}$ a constant temperature of $25^{\circ} \mathrm{C}$ exists throughout the interior plaster at all the time; thus, it is possible to maintain a constant, comfortable temperature during all the time in a day and for various weather conditions.

Blockbims, brick, briquette, concrete, and autoclaved aerated concrete (AAC) are the most common type of building material used in building construction. The thermophysical properties of these materials are tabulated in Table 3.

In Fig. 14, the highest heat gain values of NC, blockbims, briquette, AAC, brick, and PC100 walls (W1) are compared with respect to wall thickness due to the south direction. The period of the highest heat gain takes place in different hours depending on thermophysical properties and thermal storage capabilities of the building material. For all wall material, the heat gain values decrease since the wall thickness or heat resistance increases. Fig. 14 depicts as to which thickness of $\mathrm{NC}$ wall corresponds to the thicknesses of blockbims, briquette, brick, AAC, PC100, or each other. It is observed that heat gain for the PC100 wall with 10 $\mathrm{cm}$ thickness corresponds to $29.7 \mathrm{~cm}$ of briquette, $14.3 \mathrm{~cm}$ of blockbims, $24.7 \mathrm{~cm}$ of brick walls. Besides, the value of heat gain for the $\mathrm{NC}$ wall with a thickness of $20 \mathrm{~cm}$ is equal to the value of heat gain for briquette and brick with the thicknesses of $14.2 \mathrm{~cm}$ and $11.9 \mathrm{~cm}$, respectively. The results revealed

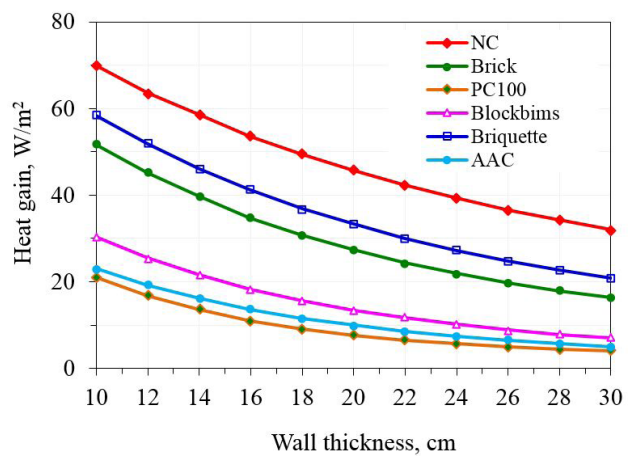

Figure 14. Daily variation of the highest heat gains of selected walls (W1) with respect to their thicknesses due to south direction 


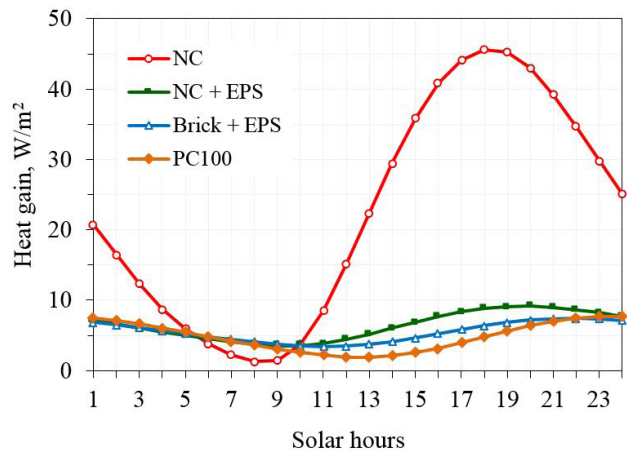

Figure 15. Comparison of the daily heat gain variations of $\mathrm{NC}$ wall (W1), PC100 wall (W1), Brick and NC walls with EPS insulations (W3)

that using lightweight structures such as PC100, EPC50 in the building, thermal comfort conditions can be achieved with minimum energy consumption for both winter and summer seasons. It is recommended to all users who use the light-weight concrete constructions in their buildings.

Fig. 15 shows a comparison of the daily heat gain variations of NC wall (W1), PC100 wall (W1), Brick, and NC walls with EPS insulations (W3). Daily total heat gain values are calculated as $535.50 \mathrm{~W} / \mathrm{m}^{2}, 152.99 \mathrm{~W} / \mathrm{m}^{2}, 130.77 \mathrm{~W} / \mathrm{m}^{2}$, and $115.21 \mathrm{~W} / \mathrm{m}^{2}$ for NC wall, NC + EPS wall, Brick + EPS wall and PC100 wall, respectively. It is seen that the thermal performance of the PC100 wall is better than NC, NC + EPS, and Brick + EPS walls. Furthermore, the lowest heat gain values are obtained for the PC100 wall at the hours between 12 and 17 when the ambient temperature is very high. Therefore, when capacity, initial and operating cost of air conditioner systems is thought, light-weight concrete is a very suitable material for both masonry and structural applications.

Fig. 16 is plotted for determining the relation between thermal diffusivity and heat gain, where the program is performed to estimate the daily heat gain values by using Eq. (12) as an input for the wall configuration of W1. As thermal diffusivity increases, the heat gain also increases; thus, for $\alpha=0.3 \mathrm{~mm}^{2} / \mathrm{s}$, the lowest amplitude of the heat gain appears while for $\alpha=1.5 \mathrm{~mm}^{2} / \mathrm{s}$, the highest amplitude of the heat gain value occurs. Furthermore, increasing the thermal diffusivity causes the maximum and the minimum peaks of

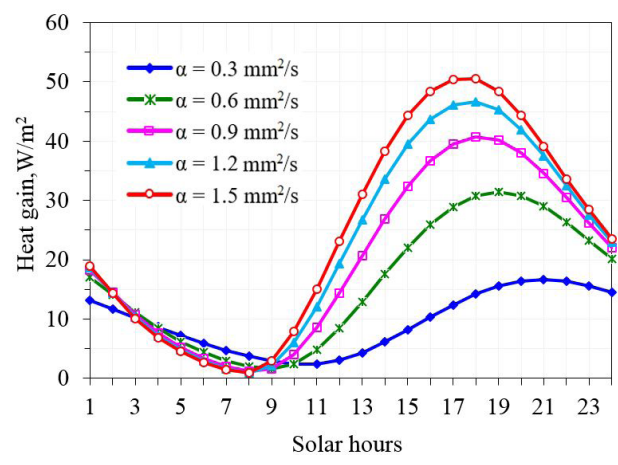

Figure 16. Thermal diffusivity versus heat gain. the daily heat gain to appear earlier. For $\alpha=0.3 \mathrm{~mm}^{2} / \mathrm{s}$, the minimum and the maximum peaks of the daily heat gain appear at 10 and $21 \mathrm{hrs}$., respectively. On the other hand, for $\alpha=1.5 \mathrm{~mm}^{2} / \mathrm{s}$, the minimum and the maximum heat gain peaks appear at 8 and 18 hrs., respectively. Hence, for a lower value than $\alpha=0.3 \mathrm{~mm}^{2} / \mathrm{s}$, the minimum peak of the heat gain and the maximum peak of the sol-air temperature coincide; moreover, the maximum peak of heat gain occurs when solar radiation does not exist and that reduces the cooling load efficiently.

Therefore, selecting a material with lower thermal diffusivity and thermal conductivity for a masonry construction can help to reduce the cooling load of a building and capacity of an HVAC system and can maintain comfortable conditions at even higher ambient air temperatures. Since the energy consumption due to heating or cooling of a building system is so enormous, the thermal insulation effect of the elements is so attractive and shows promising potential for development.

\section{CONCLUSION}

In this study, experimental and theoretical investigations were both performed to find the best building wall or roof type with high thermal insulating characteristics. The following conclusions can be drawn:

1. Thermal properties of the building materials have a profound impact on the enhancement the heat gain and surface temperature values. In particular, thermal diffusivity is a crucial property, and materials with low thermal diffusivity give the small amplitude of heat gain value. In all types of roofs and walls, the highest and the lowest heat gain value detected for the NC and PC100 walls, respectively.

2. The result of regression analysis indicates that a strong positive relationship $\left(R^{2}=0.99\right)$ exists between thermal diffusivity and conductivity values. As thermal diffusivity increases, the heat gain also increases; thus, for $\alpha=0.3 \mathrm{~mm}^{2} / \mathrm{s}$, the lowest amplitude of the heat gain appears while for $\alpha=1.5 \mathrm{~mm}^{2} / \mathrm{s}$, the highest amplitude of the heat gain value occurs.

3. The results indicated that the reductions in heat gain values were obtained as $63.17 \%$ for the EPC50 wall and $83.21 \%$ for PC100 wall with a commonly used thickness of $20 \mathrm{~cm}$, respectively, corresponding to conventional concrete $(\mathrm{NC})$.

4. Daily total heat gain values are calculated as $535.50 \mathrm{~W} / \mathrm{m}^{2}, 152.99 \mathrm{~W} / \mathrm{m}^{2}, 130.77 \mathrm{~W} / \mathrm{m}^{2}$, and $115.21 \mathrm{~W} /$ $\mathrm{m}^{2}$ for NC wall, NC + EPS wall, Brick + EPS wall and PC100 wall, respectively. The results show that the ther- 
mal performance of $\mathrm{PC} 100$ building material is better than the NC + EPS and Brick + EPS wall constructions.

5. A material with lower thermal conductivity and diffusivity for a masonry construction should be selected for reducing heat gain or loss of a building and capacity of an HVAC system size, and also can maintain comfortable conditions. As a result, cost of the HVAC system and operating cost will be decreased.

\section{NOMENCLATURE}

\begin{tabular}{|c|c|}
\hline C & specific heat (kJ/kg K) \\
\hline $\mathrm{h}_{\mathrm{i}}$ & $\begin{array}{l}\text { combined heat transfer coefficient at the inner } \\
\text { surface }\left(\mathrm{W} / \mathrm{m}^{2} \mathrm{~K}\right)\end{array}$ \\
\hline$h_{0}$ & $\begin{array}{l}\text { combined heat transfer coefficient at the outer } \\
\text { surface }\left(\mathrm{W} / \mathrm{m}^{2} \mathrm{~K}\right)\end{array}$ \\
\hline & complex arguments \\
\hline & radiation heat flux on tilted surface $\left(\mathrm{W} / \mathrm{m}^{2}\right)$ \\
\hline$I_{b T}$ & $\begin{array}{l}\text { beam radiation heat flux on tilted surface (W/ } \\
\left.\mathrm{m}^{2}\right)\end{array}$ \\
\hline$I_{d T}$ & $\begin{array}{l}\text { diffuse radiation heat flux on tilted surface } \\
\left(\mathrm{W} / \quad \mathrm{m}^{2}\right)\end{array}$ \\
\hline $\mathrm{I}_{\mathrm{rT}}$ & $\begin{array}{l}\text { reflected radiation heat flux on horizontal sur } \\
\text { face }\left(\mathrm{W} / \mathrm{m}^{2}\right)\end{array}$ \\
\hline & thermal conductivity (W/m K) \\
\hline $\mathrm{I}$ & thickness $(\mathrm{m})$ \\
\hline & time period (h) \\
\hline $\mathrm{t}$ & time $(s)$ \\
\hline & ambient air temperature $\left({ }^{\circ} \mathrm{C}\right)$ \\
\hline $\mathrm{T}_{\mathrm{e}}$ & sol-air temperature $\left({ }^{\circ} \mathrm{C}\right)$ \\
\hline $\mathrm{T}_{\mathrm{r}}$ & design inside air temperature $\left({ }^{\circ} \mathrm{C}\right)$ \\
\hline
\end{tabular}

\section{Greek symbols}

$\alpha \quad$ thermal diffusivity $\left(\mathrm{m}^{2} / \mathrm{s}\right)$

$\alpha_{\mathrm{s}} \quad$ absorptance of surface

$\rho \quad$ density $\left(\mathrm{kg} / \mathrm{m}^{3}\right)$

$\omega_{j} \quad$ complex frequency

$\delta \quad$ declination

$\varepsilon \quad$ emissivity of a surface

$\Delta \mathrm{R} \quad$ difference between long-wave radiation inci dent on the surface from the sky $\left(\mathrm{W} / \mathrm{m}^{2}\right)$

$\tau, \tau_{n}, \tau_{n p}$ dimensionless time terms

$\rho$ ground reflectance

$\omega \quad$ hour angle

$\phi \quad$ latitude angle

$\gamma \quad$ surface azimuth angle

\section{Subscripts}

AEC air-entrained concrete

EPC expanded perlite concrete

i inside

$\mathrm{N}$ number of layers

$\mathrm{N}$ number of the last layer

NC normal concrete

o outside

PC pumice concrete

RC rubberized concrete

\section{REFERENCES}

1. Yumrutaş R, Kaşka Ö, Yıldırım E. Estimation of total equivalent temperature difference values for multilayer walls and flat roofs by using periodic solution. Building and Environment 42 (2007) 1878-1885.

2. Bansal K, Chowdhury S, Gopal MR. Development of CLTD values for buildings located in Kolkata, India. Applied Thermal Engineering 28 (2008) 1127-1137.

3. Yumrutas R, Unsal M, Kanoglu M. Periodic solution of transient heat flow through multilayer walls and flat roofs by complex finite Fourier transform technique. Building and Environment 40 (2005) 1117-1125.

4. Wang SK. Handbook of air conditioning and refrigeration, McGraw-Hill, New York, 2001.

5. ASHRAE. ASHRAE handbook-fundamentals, ASHRAE, Atlanta, 1993.

6. Zainal OA, Yumrutas R. Validation of periodic solution for computing CLTD (cooling load temperature difference) values for building walls and flat roofs. Energy 82 (2015) 758-768.

7. ACI Committee 213. Guide for Structural Lightweight Aggregate Concrete, American Concrete Institute ISBN: 978-0-87031-897-9, 2014.

8. Yunsheng X, Chung DDL. Effect of sand addition on the specific heat and thermal conductivity of cement. Cement and Concrete Research 30 (2000) 59-61.

9. Khan MI. Factors affecting the thermal properties of concrete and applicability of its prediction models. Building and Environment 37 (2002) 607-614.

10. Kim K, Jeon S, Kim J, Yang S. An experimental study on thermal conductivity of concrete. Cement and Concrete Research 33 (2003) 363-371.

11. Chi JM, Huang R, Yang CC, Chang JJ. Effect of aggregate properties on the strength and stiffness of lightweight concrete. Cement and Concrete Composites 25 (2003) 197-205.

12. Howlader MK, Rashid MH, Mallick D, Haque T. Effects of aggregate types on thermal properties of concrete. ARPN Journal of Engineering and Applied Sciences 7 (2012) 900-907.

13. Różycka A, Waldemar P. Effect of perlite waste addition on the properties of autoclaved aerated concrete. Construction and Building Materials 120 (2016) 65-71.

14. Benazzouk A, Douzane O, Mezreb K, Laidoudi B, Que'neudec M. Thermal conductivity of cement composites containing rubber waste particles: Experimental study and modeling. Construction and Building Materials 22 (2008) 573-579.

15. Kilincarslan \$̧, Metin D, Mehmet A. The effect of pumice as aggregate on the mechanical and thermal properties of foam concrete. Arabian Journal of Geosciences 11 (2018) 289. 
16. Liu MYJ, Alengaram UJ, Jumaat MZ, Mo KH. Liu. Evaluation of thermal conductivity, mechanical and transport properties of lightweight aggregate foamed geopolymer concrete. Energy and Buildings 72 (2014) 238-245.

17. Yun TS, Jeong YJ, Han TS, Youm KS. Evaluation of thermal conductivity for thermally insulated concretes. Energy and Buildings 61 (2013) 125-132.

18. Paki T, Yesilata B. Physico-mechanical and thermal performances of newly developed rubber-added bricks. Energy and Buildings 40 (2008) 679-688.

19. Somayaji, S. Civil Engineering Materials, Upper Saddle River: Prentice Hall, ISBN 0-13-083906-X, p. 129, 2001.
20. Oktay H, Yumrutaş R, Akpolat A. Mechanical and thermophysica properties of lightweight aggregate concretes. Construction and Building Materials 96 (2015) 217-225.

21. BS 6073-1:1981. Precast concrete masonry units - Part 1: Specification for precast concrete masonry units, British Standards Institution, 1981.

22. Duffie JA, Beckman WA. Solar engineering of thermal process, Wiley, New York, 1980.

23. ASM International Materials Properties Database Committee, Thermal Properties of Metals, ISBN 0-87170-768-3, 2002. 